\title{
Covid-19: Keep essential malaria services going during pandemic, urges WHO
}

\author{
Jacqui Thornton
}

London

Deaths from malaria in sub-Saharan Africa could return to levels last seen 20 years ago because of severe disruptions in access to nets and medicines during the covid-19 pandemic, a new modelling analysis has shown

The World Health Organization is urging countries to do their utmost to safely maintain essential malaria control services, especially during a "critical window of opportunity" before the peak season, which follows the rainy season. Otherwise, WHO warns, deaths could double from 380000 in 2018 to 769000 in $2020{ }^{1}$

Speaking ahead of World Malaria Day on 25 April, WHO's regional director for Africa, Matshidiso Moeti, said, "We haven't seen mortality levels like that in 20 years. We must not turn back the clock."

WHO has developed new guidance on essential health services to be delivered in covid-19 settings including information on vector control and chemoprevention, testing, treatment of cases, clinical services, supply chains, and laboratory activities. ${ }^{2}$

Abdourahmane Diallo, CEO of the RBM Partnership to End Malaria, who was minister of health for Guinea from 2016 to 2018, said, "Countries with fragile health systems are facing hard—at times impossible—choices: how to protect their citizens against this new threat and at the same time stave off existing killer diseases like malaria. We have a precious window in which to act before the arrival of peak malaria season in many parts of Africa and the further spread of covid-19 across the continent."

\section{Window of opportunity}

The modelling analysis was conducted by WHO in collaboration with partners including PATH, the Malaria Atlas Project, and the Bill \& Melinda Gates Foundation. It considers nine scenarios for potential disruptions in access to core malaria control tools during the covid- 19 pandemic in 41 countries and the potential resulting increases in cases and deaths.

Under the worst case scenario, in which all insecticide treated net campaigns are suspended and access to effective antimalarial medicines falls by $75 \%$, malaria deaths in sub-Saharan Africa in 2020 would reach an estimated 769000.
The WHO's world malaria report 2019 showed that sub-Saharan Africa accounted for about $93 \%$ of all malaria cases and $94 \%$ of deaths in 2018, from an estimated 228 million cases and 405 000 deaths worldwide. ${ }^{3}$ WHO said that, while the number of reported cases of covid-19 in sub-Saharan Africa represented only a small proportion of the global total, cases were increasing every week. ${ }^{3}$ Latest figures showed 16829 confirmed cases of covid-19 in Africa. ${ }^{4}$

This means that countries throughout the region have a critical window of opportunity to minimise disruptions in malaria prevention and treatment and to save lives at this stage of the covid-19 outbreak.

\section{Control campaigns}

Mass vector control campaigns should be accelerated, says WHO, ensuring protection for health workers and communities against covid-19 transmission. Preventive therapies for pregnant women and children must be maintained, it advises. Prompt diagnostic testing and effective antimalarial medicines are also essential to prevent a mild case of malaria from progressing to severe illness and death.

WHO and partners commended the leaders of Benin, the Democratic Republic of the Congo, Sierra Leone, and Chad for initiating insecticide treated net campaigns during the pandemic. WHO has admitted that its analysis is subject to uncertainties, such as limited understanding of the spread of covid-19, its epidemiology, and its interactions with malaria.

"The model will be updated as such data become available, and countries will be provided with relevant information to tailor their responses accordingly," a spokesperson said.

World Health Organization. The potential impact of health service disruptions on the burden of malaria: a modelling analysis for countries in sub-Saharan Africa. Apr 2020 https://apps.who.int/iris/handle/10665/331845.

2 World Health Organization. Jointly addressing endemic malaria and pandemic COVID-19. 2020. https://www.who.int/malaria/areas/epidemics_emergencies/covid-19/en/.

3 World Health Organization. World malaria report 2019. 4 Dec 2019. https://www.who.int/ publications-detail/world-malaria-report-2019.

4 World Health Organization. Covid-19 dashboard. Apr 2020. https://covid19.who.int/. Published by the BMJ Publishing Group Limited. For permission to use (where not already granted under a licence) please go to http://group.bmj.com/group/rights-licensing/ permissions 